\title{
A SURVEY ON MANAGEMENT OF GASTRO OESOPHAGEAL REFLUX IN INFANTS, ACROSS THE UNITED KINGDOM
}

\author{
S. Valappil ${ }^{1}$, C. Ramesh ${ }^{2}$
}

${ }^{l}$ Neonatology, Chelsea \& Westminster Hospital, ${ }^{2}$ Neonatal Unit, Watford General Hospital, London, UK

Aims: To explore current practices and availability of local guidelines on diagnosis and management of Gastro Oesophageal Reflux (GOR) in infants, among clinicians in the neonatal units across England, Scotland, Wales and Northern Ireland.

Methods: An online survey was sent to Consultants in 226 Neonatal units across the United Kingdom. The responses were divided into two groups - depending on use of medications for "suspected" GOR. Further questions focussed on diagnostic criteria, management strategies, choice of medications if used, and local guidelines.

Results: 213 Consultants from 152 different neonatal units (67.3\% of the 226 units) completed the survey.

\begin{tabular}{|l|l|l|}
\hline & "yes group" $(\mathrm{n}=165) 77.5 \%$ & "no group" $(\mathrm{n}=48) 22.5 \%$ \\
\hline Level 3 unit $(\mathrm{n}=67)$ & $70.1 \%$ & $29.9 \%$ \\
\hline Level 2 unit $(\mathrm{n}=97)$ & $85.6 \%$ & $14.4 \%$ \\
\hline Level 1 unit $(\mathrm{n}=37)$ & $81.1 \%$ & $18.9 \%$ \\
\hline \hline not specified $(\mathrm{n}=12)$ & $41.6 \%$ & $58.4 \%$ \\
\hline \hline
\end{tabular}

[Responses to the survey]

$77.5 \%(\mathrm{n}=165)$ used medications for "suspected" GOR.

As initial step, all clinicians use supportive measures. 37\% of the "yes group" also start empirical treatment initially.

The commonest medications are Gaviscon (71\%) as first line, and a combination of Domperidone and Ranitidine (32\%) as second line. 39\% use prokinetic Erythromycin. $62 \%$ use pH probe to investigate GOR.

$81 \%$ do not have local guidelines for GOR.

Conclusions: Whilst GOR is a common problem especially in preterm and some term neonates, there is lack of consensus on management. This survey highlights the need for evidence based guidelines, .on management of gastro-oesophageal reflux in infants. 